\title{
EVOLVING TO ADDRESS GLOBAL CLIMATE CHANGE AND THE SCALE OF PUBLIC INTERACTIONS
}

\author{
JAN INGLIS \\ Director, Integrative Learning Institute, Nelson, British Columbia, Canada
}

\begin{abstract}
Global climate change is complex to address. It will require people to interact publicly as well as set policy, as a crucial part of addressing it. To date, skills for effective public interaction - where such interactions even exist - do not measure up to the demands of such global complexity. Hierarchical complexity is used to analyze common forms of public talk and interaction. Its premises are applied to approaches to conduct public discourse, including postformal approaches. The Scale of Public Interactions is introduced and indicates that Metasystematic stage approaches to climate change hold the most potential for addressing it.
\end{abstract}

KEYWORDS: Hierarchical complexity, public discourse, Scale of Public Interactions.

Climate change may well be the biggest impetus to evolve advanced survival skills that our species has collectively faced to date. The issue of climate change-and its shadow issue of peak oil-has catapulted into mainstream attention, increasing awareness and inducing a sense of urgency that climate change will impact us all, if it is not already doing so. More important is the growing recognition that human activity bears a great deal of responsibility for these conditions. Yet, even with forecasts of increased catastrophic changes, there are few, if any, comprehensive plans for how it can be addressed by us all. It seems postformal thought is required to even recognize the need for comprehensive planning.

This groundswell of attention through newspapers, books, movies, concerts, conferences, and television and radio talk shows demonstrates a kind of talk that does not generate the comprehensive public response we need at the local to global levels. This is due to at least the following related dynamics.

First, much of "the talk" stays under the blanket term "climate change," which is too vague and abstract and does not differentiate any of the specifics comprising it. Rather than being "one thing," climate change is a complex of complex issues made up of many interconnected sub-issues at many scales worldwide from lawn maintenance and building codes to population growth, subsistence practices of clearing old-growth forests, and gas flaring practices in oil processing, to terrorist

Address correspondence to Jan Inglis, BS, BA, 1823 Creek St., Nelson, BC, Canada V1L1M8. E-mail: janinglis@ telus.net 
acts and countless others - all reflecting many different values, needs, and resulting behaviors. Responses to each such cause require different types of focused attention-impossible when we keep referring to this generalized topic.

A second dynamic is that this "talk" involves only one-way communication, much of which is aimed at getting the governments to "fix it." This casts others into the role of passive and detached audience instead of essential interactive participants and co-responsible actors. Although pressuring governments in their role of organizing and enforcing policy is very important, we all have created this issue, and we all need to be engaged in diverse ways to respond to it.

Thirdly, to make decisions about complex public issues in general-not only climate change-requires that we change the aforementioned first and second dynamics, and also ultimately that we interact publicly. However, if the quality of interactions we typically have on other complex issues is an indicator, it seems unlikely that we have adequate interactive processes to address climate change. Most common forms of public interaction range from Concrete stage 8 to Systematic stage 11 in the Model of Hierarchical Complexity. The limits of these stages of performance for responding to climate change are highlighted via the examples of interactions that follow. ${ }^{1}$ These are followed by discussion of a postformal approach at Metasystematic stage 12 .

Stage 8 Concrete Interactions tend to be simple reporting of events and, without structure, such interactions slide to the basic common denominator of casual talking. At dinner parties, sitting next to someone on a plane, or in the market, amid chatting about isolated events there often is light mention of another hot summer, forest fires, or unusual storms. At this stage, there is no exploration of observations, concerns, or differences.

Stage 9 Abstract Interactions seek out differences, often combatively and often as opinionated assertions. For example, absolutist-style declarations of what should be done, who is" bad" at dealing with this problem, and who should be in charge of climate change solutions are proclaimed by individuals such as those identified with environmental groups or political parties. Although this interaction amplifies the topic of climate change, it also ensures a "safe distance" from action by making judgments about the leadership quality of those expected to take care of things. It does not provide logical reasons for statements that are made or welcome other perspectives if they differ.

Stage 10 Formal Interactions provide logical reasoning or empirical evidence and give a road map for groups who want to "do something" and not just sit around and talk in the face of this crisis. For example, conferences on climate change are often filled with data from experts and short action-planning sessions. At the formal stage, defining "the" problem and picking "a" tangible solution makes sense. This is the typical basis of strategic planning talk. But because the problem analyses miss a number of controlling variables involved, the conceived interventions are too narrow and disconnected to match the complexity and interconnected dynamics of climate change. This results in ineffective "bandage" treatments. For example, there is great enthusiasm to grow corn as a biofuel solution without considering the ripple effects on water conservation, land use, and food production. The inability of formal-stage thinking to consider ripple effects plays a major role in humans' contributions to climate change in the first place. 
Stage 11 Systematic Interactions seek to get beyond formal-stage mechanistic reasoning to include broader, big picture perspectives on climate change. Facilitated dialogue or conversation cafés support deep listening to concerns about water quality, world famine, flooding, species loss, and the angst of seeing the impact of our own lifestyle choices. There is hope that through being more caring, aware, and inclusive, capacities will emerge to create positive change. Multiple variables are recognized as possible causal relations, alone or in combinations with others. They can be described as contributing to climate change. Yet, the pragmatic steps of how the necessary priorities, choices, and actions will be made to implement that change are left undefined. Although Stage 11 is the first stage of postformal thought, and its processes greatly develop sensitivity and big-picture awareness, it is not adequate to figure out what to do next with all that information. That task requires the next stage of postformal thought, Stage 12.

The aforementioned forms of interaction do not provide the qualities of structure, focus, and follow-through needed for their participants to see, own, and address the many complex layers that make climate change problematic. They are quantified in the Scale of Public Interactions (Figure 1). In summary, at Stages 8 to 10 one's perspective is assumed to be sufficient and/or the only perspective worth considering. Stage 11 welcomes more perspectives as long as they fit standards set for sensitive interpersonal awareness and behavior. As a result, any coordinated responses to climate change are blocked at these stages due to ideology and solution wars among them. A coordinated, comprehensive approach is necessary to mobilize the good intentions available at each stage-and put them to work.

Stage 12 Metasystematic Approaches to Public Interactions address the complexity of climate change by realizing that coordination of multiple systems-

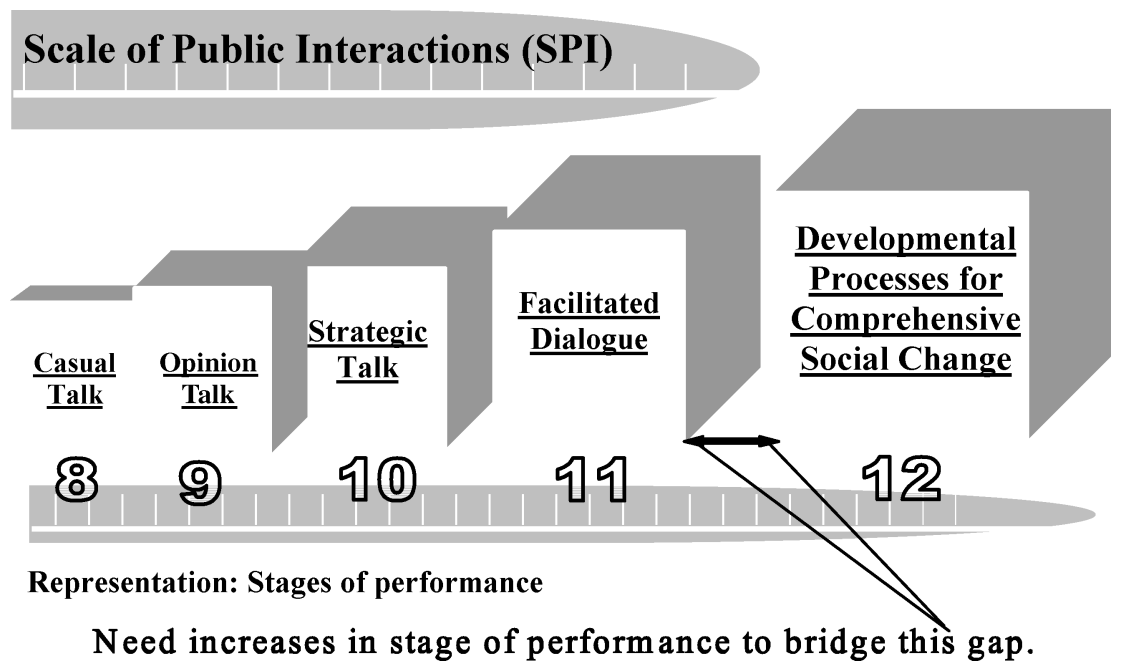

Figure 1. The scale of public interactions (SPI).

Copyright (C) 2006-2008 by Jan Inglis and Sara Nora Ross. Reproduced with permission. 
and all the complexity that comprises them-is required. Models of climate change need to be tested, the results compared, and to the extent possible, the assumptions examined. Stage 12 reasoning understands that to address complex issues means to be comprehensive. To be comprehensive means multiple options must be generated by, and make sense to, diverse perspectives from Stages 8 to 12, including the models generated at the Systematic stage 11. This is because multiple actions need to be taken by multiple actors. Those actors work in multiple organizations, governments, and communities. Decisions will be needed about which combinations of actions are necessary and hopefully sufficient to meet the outcomes desired. Multiple actions range from individually initiated actions (e.g., driving less, recycling) to policy development (e.g., tighter emissions standards, recycling mandates, water-use restrictions) to infrastructure re-organization (e.g., public transit systems), to investment, development, and incorporation of new technologies (e.g., alternative power generators). To rely on only government and policy would result in only partial responses, which are inadequate at Stage 12's insight that policy is only part of the picture.

Policy change is necessary but not sufficient because root causes of climate change are maintained in the tangle of diverse values, needs, and behaviors within and among individuals and many social structures (e.g., see Brainard, 2007 and Grant, 2007). We need structured interaction processes so we can untangle and coordinate them. Such comprehensive processes cannot be for only those with special skills but must engage the wider population of actors. Choices to take actions to reduce our ecological footprint will not occur without individuals and institutions making tradeoffs that have implications for our current ways of life-individually and collectively. For there to be sustainable commitment to implementing these choices, our public interaction processes must support those with different perspectives. People need to focus long enough with enough structure to carefully weigh these implications. If they can do that, then they can reach considered decisions and be motivated to implement them, even when it "costs" to do so. This type of developmentally structured deliberative decision-making process ${ }^{2}$ may help us move beyond the sense of overwhelm and immobility in which we are stuck. These changes have to happen for us to evolve to meet the complexity of issues-within-issues of climate change. Using Stage 12 interactions means we are, as Einstein suggested, moving beyond the kind of thinking that created the problem.

\section{NOTES}

1. For further discussion and examples see Inglis (2007).

2. Research by Ross (2007) suggests that such processes, when well structured, can increase participants' stages of reasoning about complex issues.

\section{REFERENCES}

Brainard, B. 2007. Social scientists must help policy makers respond to climate change, report says. Chronicle of Higher Education. http://chronicle.com/subscribe/login?url $=/$ daily/2007/09/2007091403n.htm (Accessed 17 September 2007.) 
Grant, Lyle K. 2007. Peak oil as a behavioral problem. http://findarticles.com/ p/articles/mi_qa4032/is_200704/ai_n19433538 (Accessed 16 September 2007.)

Inglis, J. 2007. Matching public interaction skills with desired outcomes. International Journal of Public Participation 1(2):2-17. http://www.iap2.org/ associations/4748/files/Journal_Issue2_Inglis.pdf

Ross, S. N. 2007. Effects of a structured public issues discourse method on the complexity of citizens' reasoning and local political development. Ph.D. dissertation, Union Institute \& University. 